\title{
O uso do livro didático por professores de Educação Física: uma primeira impressão
}

\author{
Rogério Zaim de Melo ${ }^{a *}$, Deyvid Tenner de Souza Rizzo ${ }^{a}$
}

Palavras Chave:

Professor;

Livro didático;

Educação Física;

Escola.

\section{Keywords:}

Teacher;

Textbook;

Physical Education;

School;

\section{Palavras Chave:}

\section{Maestro;}

Libro didáctico;

Educación Física;

Escuela.

\begin{abstract}
RESUMO
O presente estudo objetiva verificar quais são as primeiras impressões dos professores de Educação Física de Corumbá-MS - que iniciaram o ano de 2019 com o desafio de utilizar o livro didático frente ao material escolhido, observando se eles participaram do processo de escolha desse material e se acreditam ser possível desenvolver com seus alunos o que é proposto no livro. A pesquisa é de natureza qualitativa e a amostra de sujeitos é composta por nove professores de Educação Física. Os resultados indicam a necessidade de um processo mais democrático para sistematização e organização do livro didático e aponta a importância desta ferramenta para a práxis pedagógica do professor de Educação Física, contudo, é destacado que a autonomia profissional não deve ser suprimida no uso deste material.
\end{abstract}

\begin{abstract}
The present study aims to verify the first impressions of the PE teachers in Corumbá-MS. Who began the year 2019 with the challenge of using the textbook - in front of the chosen material, observing if they participated in the process of choosing that material and if they believe that it is possible to develop with their students what is proposed in the book. The research is qualitative in nature and the sample of subjects is composed of nine PE teachers. The results indicate the need for a more democratic process for systematization and organization of the didactic book and points out the importance of this tool for the pedagogical praxis of the teacher of Physical Education, however, it is emphasized that professional autonomy should not be suppressed in the use of this material.
\end{abstract}

\section{RESUMEN}

El presente estudio tiene como objetivo verificar las primeras impresiones de los maestros de Educación Física en Corumbá-MS, quienes comenzaron el año 2019 con el desafío de usar el libro de texto, frente al material elegido, observando si participaron en el proceso de elegir ese material. y si creen que es posible desarrollar con sus alumnos lo que se propone en el libro. La investigación es de naturaleza cualitativa y la muestra de sujetos está compuesta por nueve profesores de Educación Física. Los resultados indican la necesidad de un proceso más democrático para sistematización y organización del libro didáctico y apunta la importancia de esta herramienta para la praxis pedagógica del profesor de Educación Física, sin embargo, es destacado que la autonomía profesional no debe ser suprimida en el uso de este material.

\footnotetext{
a Universidade Federal do Mato Grosso do Sul, Campus do Pantanal, Curso de Educação Física Corumbá, MS, Brasil.
}

*Autor correspondente:

Rogério Zaim de Melo

E-mail: rogeriozmelo@gmail.com 


\section{APRESENTAÇÃO}

Embora seja um constante alvo de críticas (Barroso, 2015), o livro didático é um dos principais instrumentos utilizados pelos professores no processo de ensino e aprendizagem, na produção e transmissão dos conhecimentos, sendo considerado fundamental no processo de escolarização (Bittencourt, 2004). "Impulsionados por inúmeras situações adversas, grande parte dos professores brasileiros o transformaram no principal ou, até mesmo, o único instrumento a auxiliar o trabalho nas salas de aula." (Silva, 2012, p. 806). Na atualidade, o "livro didático" (Puchta; Oliveira, 2015) coexiste na escola com inúmeros outros recursos: os audiovisuais (filmes, músicas), os mapas, os softwares didáticos e a internet.

Neste estudo, adota-se o conceito cunhado por Rodrigues e Darido $(2011$, p. 2), que definem o livro didático como: "o conjunto dos manuscritos produzidos para o professor e para o aluno. O conteúdo do livro do professor e do aluno será idêntico ou semelhante, mas as características de cada um deles serão distintas." Sendo assim, existe uma relação de dependência entre professor/aluno e o uso que se faz do livro didático.

0 presente estudo tem o objetivo de verificar quais são as primeiras impressões dos professores de Educação Física de Corumbá-MS - que iniciaram o ano de 2019 com o desafio de utilizar o livro didático - frente ao material escolhido, observando se eles participaram do processo de escolha desse material e se acreditam ser possível desenvolver com seus alunos o que é proposto no livro.

\section{ALGUNS APONTAMENTOS HISTÓRICOS}

No Brasil há registros da utilização do livro didático, datados do início do século XIX. O Colégio Pedro II - criado em 1838 para atender a elite brasileira importava manuais didáticos franceses ou traduzidos para o português, para serem utilizados nas aulas. Naquela época, os custos para a produção de livros genuinamente brasileiros eram altos e a imprensa imperial não conseguia atender a demanda de publicação de textos didáticos (Silva, 2012).

Essa situação começa a mudar efetivamente no início governo de Getúlio Vargas, quando foi criada uma legislação específica para o livro didático e instalou-se o Instituto Nacional do Livro (INL) - órgão público que devia zelar e criar mecanismos para ampliar a produção do livro didático. "A partir de então, os livros didáticos passaram a ser produzidos em larga escala, com autores brasileiros, seguindo a proposta nacionalista criada na década de 1930." (Celeste Filho; Zacheu; Castro, 2015, p. 144).

Os livros didáticos tinham como autores nomes consagrados do cenário nacional, como Olavo Bilac, por exemplo, e não professores com formação específica para cada uma das áreas de ensino a que se destinava esse material (Silva, 2012). Alguns desses livros chegaram a ser utilizados nas salas de aulas por mais ou menos 50 anos (Soares, 1996). A cartilha "Caminho Suave", embora datada de 1948, teve mais de 40 milhões de exemplares vendidos até 1990, quando foi "aposentada" pelo Ministério da Educação (MEC), conforme registram Peres, Vahl e Thie (2016).

Durante os anos de 1940 a 1960, não houve mudanças significativas nesse cenário. Somente a partir do início da década de 1960, as modificações começaram a acontecer: os livros didáticos passaram a ser escritos por professores com formação na área para qual escrevia, dando-se preferência àqueles que estivessem em exercício nas séries às quais se destinavam os livros (Silva, 2012).

Durante a ditadura militar, dois momentos foram importantes para a consolidação do livro didático no Brasil: a criação da Comissão do Livro Técnico e Livro Didático (COLTED), por meio do acordo entre o MEC e a Agência Norte-Americana para o Desenvolvimento Internacional (USAID), que dispunha de recursos para o aumento da produção e barateamento do custo do livro didático (Celeste Filho; Zacheu; Castro, 2015); e, posteriormente, a criação do Programa do Livro Didático para o Ensino Fundamental (PLIFED), que assumiu os recursos da COLTED, extinta devido a escândalos com as empresas que transportavam os livros (Filgueiras, 2015).

Em 1985, o PLIFED é substituído pelo o Programa Nacional de Livro Didático (PNLD), que devido aos investimentos realizados pelas políticas públicas do Brasil passou a ser o maior programa de livro didático do mundo (Bitencourt, 2004). É um programa do MEC, direcionado à compra e distribuição aos alunos das escolas públicas brasileiras, de ensino fundamental e médio e da educação de jovens e adultos. Para que isso aconteça, o MEC avalia os livros e publica um guia com resumos das obras que passaram nessa triagem; após essa etapa, o guia é encaminhado para as escolas que devem escolher aqueles que melhor se adequam ao seu projeto político pedagógico (Pimentel; Vilarinho, 2017). Estima-se que, em 2009, foram adquiridos 126.110.481 exemplares, beneficiando 35.177 .899 alunos (Brasil, 2019a).

\section{LIVRO DIDÁTICO E EDUCAÇÃO FÍSICA NA ESCOLA}

Embora como demostrado anteriormente o livro didático exista no Brasil desde o Império, este é quase inexistente na Educação Física. Em consulta realizada no LIVRES - banco de dados de livros escolares brasileiros 
da Faculdade de Educação da USP - em 2019, não havia nenhum livro de Educação Física, catalogado.

Rodrigues e Darido (2011) realizaram um estudo com o objetivo de avaliar a aplicabilidade de um livro didático construído por eles sobre basquetebol, junto a cinco professores de Educação Física. Para tanto, os autores fizeram um levantamento bibliográfico sobre os livros didáticos existentes na Educação Física. De acordo com eles, a obra do professor Hudson Ventura Teixeira: "Trabalho dirigido de Educação Física", de 1983, é um dos únicos livros, senão o único, organizado com o objetivo de se dirigir aos alunos, entretanto a obra acabou sendo mais utilizada pelos professores como apoio pedagógico. Em 2007, o governo do estado do Paraná elaborou um livro didático para o ensino médio, constituído por textos elaborados por docentes da rede estadual de ensino, distribuído gratuitamente aos alunos matriculados no ensino médio público paranaense. Outras iniciativas isoladas de criação de livros didáticos para a Educação Física foram realizadas pelas secretarias estaduais de educação do estado de São Paulo, em 2008, e do Rio Grande do Sul, em 2009 (Souza Jr. et. al., 2015).

Somente em 2018, a Educação Física foi incluída no PNLD, no guia digital para a escolha do livro didático para o ano de 2019, sendo incluído pela primeira vez o componente curricular Educação Física, e aprovadas quatro coleções para a escolha das escolas: "Práticas corporais e a Educação Física escolar", "Encontros: Educação Física", "Manual para o professor de Educação Física" e "Práticas corporais e Educação Física" (Brasil, 2019b).

No final de 2018, o município de Corumbá escolheu a coleção "Encontros: Educação Física" para ser utilizada em 2019. Trata-se de uma obra de autoria coletiva, organizada em dois volumes, o primeiro direcionado a atender os dois primeiros anos do ensino fundamental e o segundo para os alunos de 3ㅇ, 4으 e 5o anos do mesmo segmento.

No texto inicial de apresentação do livro, o autor apresenta as intenções do manual de dar "subsídios para professores generalistas ou especialistas que ministram aulas para o componente curricular Educação Física nos anos iniciais do Ensino Fundamental" (Leopoldino, 2018, p. 4).

Para o 10 e $2^{\circ}$ anos são apresentadas, ao longo do volume 1 , sequências didáticas para os conteúdos: jogos e brincadeiras (5 unidades), esportes (3 unidades), ginástica (3 unidades) e dança (3 unidades). No volume 2 , são apresentadas os conteúdos e sequências didáticas para o 3ㅇ, 4 e 5ㅇaㅇ anos: jogos e brincadeiras (7 unidades), esportes (4 unidades), ginástica ( 3 unidades), danças (7unidades) e lutas ( 3 unidades). Em cada sequência há sugestões sobre a faixa etária para a qual as aulas foram elaboradas e número de aulas previsto.

\section{METODOLOGIA}

A metodologia utilizada é de natureza qualitativa, do tipo estudo de caso. Pesquisas em educação que investigam algo singular, com valor em si mesmo, segundo Lüdke e André (1998), enquadram-se nessa tipologia. A especificidade do estudo de caso se constituiu pela singularidade do cenário em questão: a utilização do livro de didático por professores de Educação Física.

Em um primeiro momento, entrou-se em contato com a Secretaria Municipal de Educação, solicitando autorização para a realização do estudo. Após essa etapa, iniciou-se a busca dos professores que atendiam aos critérios de inclusão: dar aulas nas séries iniciais do ensino fundamental; e ter sido professor da rede municipal de ensino (REME) do município de Corumbá, pelo menos nos últimos seis meses de 2018, podendo, assim, ter participado do processo de escolha do livro didático.

No início de 2019, segundo a Secretaria de Educação, o município contava com 63 professores ministrando aula nas séries iniciais do ensino fundamental. Para a composição da amostra houve uma consulta via WhatsApp com os professores, convidando-os a participarem da pesquisa e questionando se eles haviam participado da escolha do livro didático. Os professores que responderam somaram 34 e 9 se propuseram a participar da pesquisa, sendo todos docentes de Educação Física.

Os professores foram entrevistados a partir de um roteiro semiestruturado e 4 entrevistas foram realizadas presencialmente, e as 5 demais ocorreram via WhatsApp. Todas as entrevistas foram gravadas em áudio e transcritas. Os dados foram analisados e categorizados com base na técnica da análise de conteúdo, descrita por Bardin (2011). O objetivo da análise de conteúdo é compreender criticamente o sentido das comunicações, seu conteúdo manifesto ou latente, as significações ocultas ou explícitas. Para identificação do contexto coletivo e respectivos indicadores os extratos dos depoimentos obtidos em cada entrevista foram organizados em quadros gerais para permitir o cruzamento das diferentes colocações dos professores dentro de um mesmo tema.

A formação das categorias se deu de forma indutiva a partir das perguntas presentes no instrumento de pesquisa, explorando as informações recebidas buscando convergências e divergências na fala dos participantes da pesquisa, exceto na categoria formação do professor. 


\section{RESULTADOS E DISCUSSÃO}

Os dados obtidos foram analisados e distribuídos nas seguintes categorias: formação do professor; a escolha do livro; a viabilidade dos conteúdos propostos; sugestões de mudança.

\section{Formação do Professor}

O quadro a seguir apresenta o ano da formação em Educação Física dos participantes da pesquisa e aponta a existência ou não de disciplinas que abordaram alguma temática sobre o livro didático no processo de graduação:

Quadro 1. Formação.

\begin{tabular}{|lcc|}
\hline Participante & $\begin{array}{c}\text { Ano de } \\
\text { formação }\end{array}$ & $\begin{array}{c}\text { Livro didático na } \\
\text { formação }\end{array}$ \\
\hline Professor 1 & 2016 & Não \\
Professor 2 & 2013 & Não \\
Professor 3 & 2018 & Não \\
Professor 4 & 1986 & Não \\
Professor 5 & 2014 & Sim \\
Professor 6 & 1985 & Não \\
Professor 7 & 2016 & Não \\
Professor 8 & 1997 & Não \\
Professor 9 & 2015 & Sim \\
\hline
\end{tabular}

Fonte: Dados da pesquisa.

A discussão sobre a presença do livro didático é relativamente recente no cenário da Educação Física (Rodrigues; Darido, 2011; Souza Jr. et. al., 2015), implicando na ausência de debates sobre o assunto no processo de formação dos docentes participantes da pesquisa. Mesmo para aqueles que afirmaram existir professores que mencionaram o livro didático do Paraná, o debate foi incipiente, como é possível observar nas seguintes falas: "O livro didático do Paraná, mencionado pelo professor em uma de suas disciplinas." (Professor 5); "O professor da disciplina de ensino médio falou do livro público do Paraná." (Professor 9).

Diante deste cenário, caberia à Secretaria Municipal de Educação fomentar essa discussão, uma vez que a implantação do livro didático em Educação Física era inevitável no cenário público nacional, o que na prática não ocorreu, os professores sequer participaram do processo de escolha do livro.

\section{Escolha do livro}

Os 34 professores que responderam à consulta via WhatsApp afirmaram não ter participado da escolha do material. De acordo com um dos entrevistados: "A Secretaria em reunião mostrou dois livros para os docentes, e disseram que haveria uma reunião em outro dia para que o assunto fosse discutido. Se teve a reunião eu não fui." (Professor 1). Corroborando com esta fala, o professor 9 afirma: "Eu gostaria muito de participado desse processo de escolha, mas nem soube da reunião." (Professor 9). 0 professor 6 afirmou que não há livro didático no município, uma vez que o escolhido não tem volume do aluno.

Caracterizamos o livro didático como um material utilizado para se ensinar e aprender entre os atores sociais na escola. Nessa perspectiva, é importante que o professor participe do processo de seleção/ organização do livro didático a ser utilizado, pois este irá além da premissa de "adotar ou seguir um livro" nas suas ações, buscando interagir com os desafios apresentados pelo material didático e o cotidiano escolar, (re) significando, dessa forma, o processo de ensino e aprendizagem com práticas inovadoras.

Segundo o PNLD (Brasil, 2019b), os professores têm como tarefa analisar as apresentações dos livros presentes no guia disponibilizado pelo programa para escolher adequadamente os livros a serem utilizados no triênio, devendo este adequar-se ao projeto políticopedagógico da escola, aos discentes e docentes, e, principalmente, à realidade sociocultural das instituições.

Pimentel e Vilarinho (2017) baseadas em posicionamentos do corpo docente do Colégio Pedro II (referência para a escolha e elaboração de material didático no Brasil, desde o século XIX), construíram e validaram um instrumento para os docentes utilizarem durante a análise e escolha do livro didático. Para as autoras, muitas questões podem ser levantadas nesse processo, destacando-se:

[...] dificuldade para distribuir as obras entre os professores para que todos possam opinar na escolha do material; [...] a escolha de uma única coleção de livros didáticos para todos, não respeitando as individualidades; [...] o consenso como critério de escolha do livro didático nem sempre possibilita a melhor escolha. (Pimentel; Vilarinho, 2017, p. 40).

No caso do município de Corumbá, tais questões nem foram possíveis de serem levantadas, uma vez que o professor de Educação Física, o maior interessado nessa escolha, não teve a oportunidade de participar desse processo. Ou seja, foi retirada desses professores a oportunidade de se aproximar democraticamente do processo de construção de um material que tem como pano de fundo o papel de democratizar o ensino de conteúdos e saberes específicos da Educação Física. 
Surge, assim, a necessidade de conscientizar os atores sociais que "lideram" e encenam o processo de mediação didático-pedagógica para organização e seleção do livro didático do município de Corumbá, no sentido de esclarecer que esse material é um instrumento de reflexão coletiva e individual, e precisa atender à dupla exigência.

\section{Viabilidade dos conteúdos propostos}

Em geral, as práticas docentes dos partícipes do estudo estão estreitamente associadas ao uso do livro didático. Dessa forma, torna-se necessário saber as opiniões desses sujeitos acerca da eficiência e/ou ineficiência desse instrumento no processo de ensino e aprendizagem. Para isso, a seguir apresenta-se um quadro que traduz de forma sintetizada a primeira impressão dos participantes das pesquisas sobre a viabilidade das sequências didáticas propostas pelo livro didático.

Quadro 2. Conteúdos propostos

\begin{tabular}{|lcc|}
\hline Participante & $\begin{array}{c}\text { Primeira } \\
\text { impressão }\end{array}$ & Sequências didáticas \\
\hline Professor 1 & Bom & $\begin{array}{c}\text { Precisam ser melhoradas } \\
\text { Sequências incompletas }\end{array}$ \\
Professor 2 & Bom & São boas \\
Professor 3 & Muito bom & Não utilizo \\
Professor 4 & Péssimo & Em partes \\
Professor 5 & Bom & - \\
Professor 6 & Não opinou & Não \\
Professor 7 & Bem fraco & Sequências incompletas \\
Professor 8 & Razoável & Somente o livro 2 \\
Professor 9 & Razoável &
\end{tabular}

Fonte: Dados da pesquisa.

A primeira impressão causada pelo livro didático perpassa as nuances de péssimo a muito bom: 3 docentes afirmaram que o livro é bom; 2 disseram que é razoável; 1 classificou como bem fraco; 1 disse que era muito bom; 1 disse que é péssimo; 1 não opinou, pois segundo ele, o livro foi apenas indicado pela secretaria e não há livro para o aluno.

Os 3 professores que disseram que o material é bom, afirmaram que o livro serve para apoio nas aulas: "É uma ferramenta positiva no apoio às aulas." (Professor 2). "Uma boa ferramenta didática para o ensino de Educação Física." (Professor 5). Os docentes que afirmaram que o livro é razoável denunciam uma deficiência na organização dos conteúdos e limitações nos indicadores de avaliação do processo de ensino e aprendizagem. "Acredito que se tivessem mais atividades, melhor estruturado e livros de atividades para os alunos daria para usar melhor." (Professor 8).
Os professores que classificaram o livro negativamente (bem fraco e ruim) apresentam razões diferentes: para o professor 7, as atividades do livro não atendem as suas necessidades, por isso ele considerou o livro "bem fraco"; para o professor 4, o livro é péssimo, pois para ele, a Educação Física não deveria ter livro didático: "Sou contrário à colocação de livro didático de Educação Física. Acho que é antifisiológico o uso de material didático, pois a nossa atividade é $100 \%$ prática." (Professor 4 ).

Na busca de possíveis articulações didáticas para a Educação Física é necessário desafiar os abismos tradicionais e coadunar com a inovação pedagógica na educação física escolar (Silva; Souza e Martins, 2019). Nesse contexto, as falas dos professores permitem compreender que a proposta do livro didático confronta informações sobre a viabilidade dos conteúdos apresentados, principalmente se pensarmos numa proposta ligada a inovações pedagógicas que a Educação Física em geral perspectiva para sua identificação e significação no âmbito escolar.

As sequências didáticas, propostas na obra adotada em Corumbá, foram baseadas no que foi proposto para a Educação Física na Base Nacional Comum Curricular (BNCC), indicando aprendizagens essenciais para todo o ensino fundamental do Brasil. Para Neira (2018, p. 217), definir aprendizagens para "um país com dimensões continentais e tão diverso como o nosso [...] soa um tanto arrogante."

Tal arrogância se reflete na validade das sequências didáticas, alvo de críticas pelos participantes deste estudo, exceto o professor 3 , que aponta que o livro atende perfeitamente suas necessidades, e os professores 4 e 6, que não utilizam esse material. Para os outros professores: "As sequências são boas, mas incompletas, deveriam ter mais sugestões." (Professora 1); "A sequência dos livros nem sempre estão de acordo com os conteúdos elencados nos referenciais adotados. Eu pensaria em mais exemplos. Os livros poderiam ter uma sequência didática mais abrangente." (Professor 2); "Faltam outros conteúdos da Educação Física." (Professor 5); "Temos que fazer muitas buscas para complementar." (Professor 8); "O livro dois sim, o livro 1 não, as atividades propostas são muito complicadas para a capacidade dos meus alunos." (Professor 9).

É nesse contexto de críticas sobre a utilização do livro didático que se percebe um consenso intrínseco nos depoimentos dos professores, a necessidade de um movimento que assuma como eixo norteador a diversificação dos conteúdos de acordo com códigos, sentidos e significados da população a qual os docentes estão inseridos. 


\section{Sugestões de mudanças}

A partir dos depoimentos dos professores, presume-se que o livro didático utilizado pela REME de Corumbá requer mudanças. Entre as principais modificações sugeridas pelos professores destacase a necessidade de um exemplar para o aluno, não apenas para o professor. Todos os professores que estão utilizando o livro foram unânimes nesse ponto.

Para os professores 2 e 5 , o livro deveria incluir outros conteúdos da Educação Física. O professor 8 indica a necessidade de uma diversificação para as formas de avaliar e cita como exemplo de livro didático o livro "Jogo Limpo", utilizado nas aulas de Educação Física de Portugal. O professor 9 afirmou que as sequências didáticas deveriam ser revistas para atender a faixa etária dos alunos dele, pois, conforme afirmou: "Algumas atividades propostas estão além da capacidade dos meus alunos, principalmente nas unidades dos esportes para o 1 - e $2 \circ$ ano."

Com esse estudo, percebem-se alguns elementos relacionados ao processo de escolha dos livros didáticos a partir do PNLD, assinalando que não há uma disposição formalizada das escolas para uma escolha a partir de critérios teóricos, críticos, metodológicos e análises organizadas a partir dos referenciais curriculares adotados na REME.

Talvez a ausência de informação sobre os livros didáticos na formação dos professores de Educação Física reflete no uso de materiais preparados pela própria escola ou por meio de cópias, ditados ou apostilas de conteúdos preparadas pelo professor.

Num estudo sobre o abandono e permanência na carreira docente em Educação Física, Favatto e Both (2019) evidenciam que um dos motivos que originam o anseio de permanecer na docência estava atrelado o desejo de auxiliar no processo de formação dos alunos.

Para que tal aspiração mobilize os grupos de professores de Educação Física é necessária uma mudança no status docente, ou seja, a construção de uma identidade profissional atuante e crítica, que é ouvida e atendida, como por exemplo, na construção e sistematização de um livro didático, e desta forma neutralizar discursos e práticas superficiais sobre a utilização de um material didático que pode orientar, ensinar, preparar os alunos para um ciclo de vida mais ativo.

\section{CONSIDERAÇÕES FINAIS}

Sabemos que a Educação Física ainda encontra muitas dificuldades para se estabelecer na escola, seja por ordem epistemológica ou didática, assim,

1 Um dos livros didáticos de Educação Física, adotados em Portugal de autoria de José D. Costa, publicado pela editora do Porto. é importante pensar em estratégias para auxiliar o professor de Educação Física a lidar com diversas limitações, principalmente as barreiras no tocante ao desenvolvimento dos conteúdos. Nessa direção, trazemos uma problematização: como a organização de um livro didático se articulou com a Educação Física num cenário que as vozes dos atores docentes que orientam o processo de ensino aprendizagem por vezes foram silenciadas?

Com base nos objetivos preliminares apresentados para o presente estudo, advogamos a importância de um material didático sistematizado de acordo com as características e necessidades da Educação Física de cada região. Contudo, as impressões dos sujeitos dessa investigação nos levam a crer que o processo de seleção do livro didático precisa ser mais democrático, considerando principalmente a seleção dos conteúdos.

É indispensável destacar que a temática debatida neste artigo é de extrema importância para significar a eficiência da Educação Física e que estamos longe de concluí-lo. Vale salientar que o livro didático pode ser uma importante ferramenta para práxis pedagógica do professor de Educação Física, e que a autonomia profissional não deve ser suprimida no uso deste material, mas somada como mais uma unidade de conhecimento facilitadora do processo de ensino e aprendizagem.

Para se afirmar e construir um ambiente que respeite a diversidade e enalteça a autonomia de alunos, primeiramente é necessário considerar e valorizar as percepções dos professores enquanto sujeitos ativos capazes de criar e transformar a realidade social. Por fim, se um processo de organização de um livro didático como uma ferramenta importante para o professor em sua prática ignora essa premissa, inutilmente proporemos estratégias para contribuir com o trabalho docente em sua prática educativa na Educação Física escolar. Destacamos que o professor precisa de autonomia suficiente para contribuir na organização e entendimento do livro didático como um material importante para o processo de ensino aprendizagem. Entretanto, é necessário que outros estudos que envolvam a articulação do livro didático com a Educação Física sejam realizados, possibilitando reflexões sobre as possibilidades que este material pode significar para esta unidade curricular, talvez, avaliar as percepções e aprendizagens do corpo discente.

\section{REFERÊNCIAS}

Bardin L. Análise de conteúdo. São Paulo: Edições 70; 2011.

Barroso ALR. A utilização de material didático impresso para o ensino de um modelo de classificação do esporte na educação física escolar. Rio Claro. Tese [Doutorado em desenvolvimento humano e tecnologia] - Unesp; 2015. 
Bittencourt CMF. Em foco: história, produção e memória do livro didático. Educação e Pesquisa 2004;30(3):1-3.

Brasil. Ministério da Educação. Fundo Nacional de Desenvolvimento da Educação (FNDE). Programas do Livro: dados estatísticos. Brasília, DF, 2019a. [acesso em 7 mar 2019]. Disponível em: https://www.fnde.gov.br/ programas/programas-do-livro/pnld/dados-estatisticos.

Brasil. Ministério da Educação. Programa Nacional do Livro Didático (PNLD). Guia Digital. Brasília, DF, 2019b. [acesso em 7 mar 2019]. Disponível em: http://pnld.nees.com.br/ pnld_2019/componente-curricular/educacao-fisica.

Celeste Filho M, Zacheu AAP, Castro LLO. O livro didático no Brasil: uma trajetória dos tempos imperiais à contemporaneidade. In: Reis ML, Jorge M, Magnoni MGM. Cadernos de docência IV: as experiências da docência. São Paulo: Cultura Acadêmica; 2015. p. 157-67.

Favatto NC, Both J. Motivos para abandono e permanência na carreira docente em educação física. Revista Brasileira de Ciências do Esporte, 2015;41(2):127-34.

Filgueiras JM. As políticas para o livro didático durante a ditadura militar: a COLTED e a FENAME. História da Educação 2015;19(85):102.

Leopoldino LN. Encontros: Educação Física. São Paulo: FTD; 2018. 2 v.

Lüdke $M$, André MED. Pesquisa em educação: abordagens qualitativas. São Paulo: EPU; 1988.

Neira MG. Incoerências e inconsistências da BNCC de Educação Física. Revista Brasileira de Ciências do Esporte 2018;40:215-23.
Peres ET, Vahl MM; Thie VG. Aspectos editoriais da cartilha Caminho Suave e a participação da Editora Caminho Suave Limitada em programas federais do livro didático. Revista Brasileira de História da Educação 2016 Abr; 16(1);335-72.

Pimentel SRG, Vilarinho LRG. A escolha do livro didático: um instrumento de apoio ao corpo docente do ensino fundamental. Revista de Gestão e Avaliação Educacional 2017 Set; 6(13):37-52.

Puchta DR, Oliveira MAT. O livro como ferramenta pedagógica para a inserção da educação física e da ginástica no ensino público primário paranaense (fim do século XIX e início do século XX). Revista Brasileira de Ciências do Esporte 2015 Jul; 37(3):272-9.

Rodrigues HA, Darido SC. O livro didático na Educação Física escolar: a visão dos professores. Motriz: rev. educ. fis. 2011 Mar;17(1):48-62 [acesso em 7 mar 2019]. Disponível em: http://www.scielo.br/pdf/motriz/v17n1/a07v17n1.pdf.

Silva BS, Souza ACFD, Martins MZ. Desafiando o abismo tradicional: uma aproximação entre práticas inovadoras e o modelo de educação esportiva no âmbito da educação física escolar. Revista Brasileira de Ciências do Esporte, 2019. https://doi.org/10.1016/j.rbce.2019.04.003

Silva MA. A fetichização do livro didático no Brasil. Educação e Realidade 2012;37(3):803-21.

Soares MB. Um olhar sobre o livro didático. Presença Pedagógica 1996; 2(12): 53-62.

Souza Jr MBM, Amaral LV, Melo, MST, Darido, SC, Lima, RBT. Educação Física e o livro didático: entre o hiato e o despertar. Movimento 2015; 21(2): 479-97. 